\title{
Anti-inflammatory and immunomodulatory mechanisms of mesenchymal stem cell transplantation in experimental traumatic brain injury
}

Run Zhang ${ }^{1+}$, Yi Liư ${ }^{1+}$, Ke Yan ${ }^{1}$, Lei Chen², Xiang-Rong Chen ${ }^{1}$, Peng Li ${ }^{1}$, Fan-Fan Chen ${ }^{1}$ and Xiao-Dan Jiang ${ }^{1 *}$

\begin{abstract}
Background: Previous studies have shown beneficial effects of mesenchymal stem cell (MSC) transplantation in central nervous system (CNS) injuries, including traumatic brain injury (TBI). Potential repair mechanisms involve transdifferentiation to replace damaged neural cells and production of growth factors by MSCs. However, few studies have simultaneously focused on the effects of MSCs on immune cells and inflammation-associated cytokines in CNS injury, especially in an experimental TBI model. In this study, we investigated the anti-inflammatory and immunomodulatory properties of MSCs in TBI-induced neuroinflammation by systemic transplantation of MSCS into a rat TBI model.
\end{abstract}

Methods/results: MSCs were transplanted intravenously into rats $2 \mathrm{~h}$ after TBI. Modified neurologic severity score (mNSS) tests were performed to measure behavioral outcomes. The effect of MSC treatment on neuroinflammation was analyzed by immunohistochemical analysis of astrocytes, microglia/macrophages, neutrophils and T lymphocytes and by measuring cytokine levels [interleukin (IL)-1a, IL-1 $\beta, I L-4, I L-6, I L-10, I L-17$, tumor necrosis factor- $\alpha$, interferon- $\gamma$, RANTES, macrophage chemotactic protein-1, macrophage inflammatory protein 2 and transforming growth factor- $\beta 1$ ] in brain homogenates. The immunosuppression-related factors TNF-a stimulated gene/protein 6 (TSG-6) and nuclear factor-KB (NF-KB) were examined by reverse transcription-polymerase chain reaction and Western blotting. Intravenous MSC transplantation after TBI was associated with a lower density of microglia/macrophages and peripheral infiltrating leukocytes at the injury site, reduced levels of proinflammatory cytokines and increased anti-inflammatory cytokines, possibly mediated by enhanced expression of TSG-6, which may suppress activation of the NF-KB signaling pathway.

Conclusions: The results of this study suggest that MSCs have the ability to modulate inflammation-associated immune cells and cytokines in TBI-induced cerebral inflammatory responses. This study thus offers a new insight into the mechanisms responsible for the immunomodulatory effect of MSC transplantation, with implications for functional neurological recovery after TBI.

\footnotetext{
* Correspondence: jiangxiao_dan@163.com

${ }^{\dagger}$ Equal contributors

'The National Key Clinic Specialty, The Neurosurgery Institute of Guangdong

Province, Guangdong Provincial Key Laboratory on Brain Function Repair and

Regeneration, Department of Neurosurgery, Zhujiang Hospital, Southern

Medical University, Guangzhou 510282, China

Full list of author information is available at the end of the article
} 


\section{Background}

Traumatic brain injury (TBI) is a major cause of mortality and morbidity among the population worldwide [1]. The inflammatory response is regarded as a key factor in the secondary injury cascade following TBI. Activation of the inflammatory cascade is mediated by the release of pro- and anti-inflammatory cytokines [2,3]. TBI induces a strong inflammatory response characterized by the recruitment of peripheral leukocytes into the cerebral parenchyma and the activation of resident immune cells $[4,5]$. The infiltration of neutrophils, monocytes and lymphocytes to the injured site directly affects neuronal survival and death [4-7]. Moreover, activated microglia migrate to injured sites and release cytokines, chemotactic cytokines, reactive oxygen species, nitric oxide, proteases and other factors with cytotoxic effects, which may in turn exacerbate neuronal death $[6,8]$.

However, these immune cells and inflammatory mediators can also have neuroprotective effects in TBI $[3,9]$. For example, $\mathrm{T}$ lymphocytes may contribute to later repair processes in brain injury [10,11]; proinflammatory cytokines such as interleukin (IL)-1, IL-6 and tumor necrosis factor (TNF)- $\alpha$ have both deleterious and beneficial effects on neural cells $[7,12,13]$; and microglia can remove cell debris, promote tissue remodeling and exert numerous neuroprotective effects under certain conditions $[4,14,15]$. Of these, TBI-induced inflammation appears to be a key factor in secondary brain damage, which suggests that anti-inflammatory or immunoregulatory strategies could provide effective treatments for the management of TBI-induced pathology.

Previous studies have shown beneficial effects of mesenchymal stem cell (MSC) transplantation in central nervous system (CNS) injuries, including TBI, stroke and spinal cord injury animal models. The main findings of these studies suggested that MSCs improved neurological functional recovery, decreased apoptosis, increased endogenous cell proliferation, promoted angiogenesis and reduced lesion size [16]. The potential mechanisms whereby transplanted MSCs might exert beneficial effects in CNS injury include their ability to migrate to injured tissues, transdifferentiation to replace damaged neural cells and the production of growth factors by MSCs [16-18]. However, recent evidence indicates that the therapeutic effect of MSC transplantation may not be through direct cell replacement, but via modulating the host microenvironment [19]. MSCs can secrete a variety of bioactive molecules such as trophic factors and anti-apoptotic molecules, which may provide the main mechanism responsible for their therapeutic effect [20].

More recently, many studies have demonstrated that MSCs possess immunomodulatory properties [21,22]. MSCs can directly inhibit the proliferation of $\mathrm{T}$ lymphocytes and microglial cells, and can modulate the cytokine-secretion profile of dendritic cells and monocytes and/or macrophages [20,23-25]. MSCs are also known to inhibit basal and formyl-methionyl-leucyl-phenylalaninestimulated production of reactive oxygen species by neutrophils [26]. In experimental autoimmune encephalomyelitis models, MSCs inhibited myelin-specific T cells and induced peripheral tolerance $[27,28]$. The immunosuppressive effect of transplanted MSCs has also been demonstrated in acute, severe graft-versus-host disease [29] and in multiple system atrophy [30]. In addition, MSCs can induce peripheral tolerance and migrate to injured tissues, where they can inhibit the release of proinflammatory cytokines and promote the survival of damaged cells [21]. For example, the therapeutic benefit of MSC transplantation has been observed in acute lung injury [31,32], myocardial infarction [33], acute renal failure [34], cerebral ischemia [35] and Alzheimer's disease [36]. Furthermore, some studies have found an inflammation-modulatory function for transplanted stem cells. One study demonstrated anti-inflammatory effects of human cord blood cells in a rat model of stroke [37]. Another study reported that intravenous NSCs, administered during the hyperacute stage in stroke, could modulate innate cerebral inflammatory responses by interacting with peripheral inflammatory systems [38].

These studies indicate the feasibility of using MSCs to reduce cerebral inflammation and modulate the immune response after TBI. However, few studies have focused simultaneously on the effects of MSCs on inflammationassociated cytokines and immune cells in CNS injury, especially in an experimental TBI model. In this study, we therefore investigated the anti-inflammatory and immunomodulatory properties of MSCs in TBI-induced neuroinflammation using systemic MSC transplantation in a rat TBI model.

\section{Materials and methods}

Sprague-Dawley (SD) rats were purchased from the Animal Experiment Center of Southern Medical University (Guangzhou, China). Animals were housed under a 12-h light/dark cycle, with food and water freely available. Animal experimental procedures were approved by the Southern Medical University Ethics Committee. All surgery was performed under sodium pentobarbital anesthesia, and all efforts were made to minimize animal suffering.

\section{Isolation, expansion and characterization of MSCs}

MSCs were generated from the bone marrow of SD rats. Mononuclear cells were isolated by gradient centrifugation at $900 \mathrm{~g}$ for $30 \mathrm{~min}$ on Percoll (Invitrogen, Carlsbad, CA, USA) at a density of $1.073 \mathrm{~g} / \mathrm{ml}$. The cells were then washed twice with phosphate-buffered saline (PBS) and plated at $1 \times 10^{6}$ cells $/ 25 \mathrm{~cm}^{2}$ in culture flasks in $5 \mathrm{ml}$ DMEM/F12 (1:1) with 10\% fetal bovine serum. After $72 \mathrm{~h}$ 
of incubation, non-adherent cells were removed from the cultures, and fresh culture medium was added to the flasks. When the cells reached 90\% confluence, adherent cells were trypsinized, harvested and expanded [39]. Expanded cells from passages three-eight were used for further testing or transplantation.

MSCs were assessed by flow cytometry analysis of CD44, CD90 and CD105, and the hematopoietic markers CD14, CD34, CD45 and HLA-DR [40]. The primary antibodies used were fluorescein isothiocyanate-conjugated antiCD44, -CD45 and -CD105, and phycoerythrin-conjugated anti-CD14, -CD34, -CD90 and -HLA-DR. All antibodies were purchased from AbD Serotec (1:10, Kidlington, UK).

\section{Experimental groups}

SD rats were divided into three groups: (1) sham group (21 rats); (2) TBI + saline group (52 rats); (3) TBI + MSCs group (52 rats).

\section{Traumatic brain injury animal models}

TBI animal models were produced as previously described [41]. Adult male SD rats (220-250 g) were anesthetized with $2 \%$ pentobarbital $(30 \mathrm{mg} / \mathrm{kg})$ intraperitoneally and maintained at $37^{\circ} \mathrm{C}$ throughout the surgical procedure using a water-heating pad. The rats were placed in a stereotactic frame. A 6-mm-diameter craniotomy was performed over the right cortex midway between the lambda and the bregma. Injury was induced using a weight-drop hitting device (ZH-ZYQ, Electronic Technology Development Co., Xuzhou, China) with a $4.5-\mathrm{mm}$-diameter cylinder bar weighing $40 \mathrm{~g}$ from a height of $20 \mathrm{~cm}$. Rats in the sham group were subjected to the same craniotomy procedure without cortical impact.

\section{MSC transplantation}

Two hours after TBI, the rats were neurologically evaluated using a modified neurological severity score (mNSS) test. Rats with similar neurological severity scores (13-15 points) were randomly divided into two groups that received $4 \times 10^{6}$ MSCs in $100 \mu \mathrm{l}$ PBS or PBS alone, respectively, via the jugular vein.

\section{Behavioral testing}

Behavioral testing was conducted on days 1, 3, 7, 14, 21 and 28 after TBI using mNSS tests. The mNSS test includes motor, sensory, reflex and balance tests, as described previously [42]. The mNSS test is graded on a scale of $0-18$, where a total score of 18 points indicates severe neurological deficit and a score of 0 indicates normal performance; $13-18$ points indicates severe injury, 7-12 indicates mean-moderate injury, and 1-6 indicates mild injury.

\section{Measurements of brain water content}

Brain water content was measured at $72 \mathrm{~h}$ after TBI. Following anesthesia and decapitation, the brains were removed immediately and divided into two hemispheres along the midline, and the cerebella were removed. Ipsilateral hemispheres were placed on a pre-weighed piece of aluminum foil to give the wet weight and then dried in an electric oven at $100^{\circ} \mathrm{C}$ for $24 \mathrm{~h}$ [38]. The brain water percentage was calculated as follows: (wet weight - dry weight)/(wet weight).

\section{Immunohistochemistry and terminal deoxynucleotidyl transferase dUTP nick end labeling staining}

At $72 \mathrm{~h}$ after TBI, rats were anesthetized and transcardially perfused with $100 \mathrm{ml}$ cold PBS and $100 \mathrm{ml}$ of $4 \%$ paraformaldehyde in $0.1 \mathrm{M}$ PBS. The brains were then removed, post-fixed and paraffin-embedded, and consecutive coronal sections were cut at $5-\mu \mathrm{m}$ intervals from bregma $-2.0 \mathrm{~mm}$ to bregma $-7.0 \mathrm{~mm}$ to collect the entire lesioned cortex. For immunohistochemistry, slides with brain sections were deparaffinized and boiled in $10 \mathrm{mM}$ citrate buffer ( $\mathrm{pH}$ 6.0) in a microwave to expose the antigens and then blocked with $10 \%$ normal goat serum. Slides were incubated with primary antibody against glial fibrillary acidic protein (GFAP) (rabbit polyclonal to GFAP, 1:200), microglia/macrophage-specific calcium-binding protein (goat polyclonal to Iba1, 1:100, Abcam, New Territories, $\mathrm{HK}$ ), myeloperoxidase (MPO) (rabbit polyclonal to MPO, 1:100, Abcam) and CD3 (rabbit polyclonal to CD3, 1:100, Abcam) at $4^{\circ} \mathrm{C}$ overnight. Following primary antibody incubation, slides were incubated in biotin-conjugated anti-rabbit IgG or anti-goat IgG (1:100, Boster, Wuhan, China), then treated with an avidin-biotin-peroxidase system (Boster) (negative controls for immunostaining was secondary antibody only). Finally, slides were stained with diaminobenzidine, and the nucleus was counterstained with hematoxylin. Terminal deoxynucleotidyl transferasemediated dUTP nick 3 '-end labeling was performed to detect dying cells using an In Situ Cell Detection Kit (Roche, South San Francisco, CA, USA) according to the manufacturer's instructions. The number of positive cells near the injured areas was counted (8 to10 sections per brain, $500 \mu \mathrm{m}$ apart) in a blinded manner.

\section{Cytokine analysis}

To measure cytokine levels, rats were killed at 12,24 and $72 \mathrm{~h}$ after TBI or sham operation. Brains were immediately collected, and punch biopsies (5 $\mathrm{mm}$ diameter) of the injured cortex were isolated and stored at $-80^{\circ} \mathrm{C}$. The tissue was homogenized in chilled extraction buffer containing Tris- $\mathrm{HCl}$ (50 mmol/l, pH 7.2), $\mathrm{NaCl}(150 \mathrm{mmol} / \mathrm{l}), 1 \%$ Triton X-100 and $1 \mathrm{mg} / \mathrm{ml}$ protease inhibitor cocktail (Biovision, Mountain View, CA, USA) at a ratio of 1:10 (tissue: buffer), shaken for $90 \mathrm{~min}$ on ice, centrifuged at 
$12,000 \mathrm{~g}$ for $15 \mathrm{~min}$ at $4^{\circ} \mathrm{C}$ and frozen at $-80^{\circ} \mathrm{C}$ [43]. Total protein concentrations were measured using a BCA Protein Assay Kit (Thermo, Rockford, IL, USA). The levels of 12 cytokines [IL-1 $\alpha$, IL-1 $\beta$, IL-4, IL-6, IL-10, IL-17, tumor necrosis factor (TNF)- $\alpha$, interferon (IFN)- $\gamma$, RANTES, macrophage chemotactic protein (MCP)-1, macrophage inflammatory protein (MIP)-2 and transforming growth factor (TGF)- $\beta 1$ ] were determined in $1 \mathrm{mg}$ of total protein using the Rat Bio-Plex Pro Assays (Bio- Rad, Hercules, CA, USA), according to the manufacturer's instructions.

\section{Quantitative real-time polymerase chain reaction}

Total RNA was extracted from injured brain tissues at 12, 24 and $72 \mathrm{~h}$ after TBI using TRIzol Reagent (Invitrogen), according to the manufacturer's instructions. Levels of TNF- $\alpha$ stimulated gene/protein 6 (TSG-6) and nuclear factor (NF) $-\mathrm{kB}$ mRNA were quantitated using an $\mathrm{ABI}$ 7500HT Fast Real-Time PCR System (Applied Biosystems, Grand Island, NY, USA). Glyceraldehyde-3-phosphate dehydrogenase (GAPDH) was used as an endogenous control. Sequence-specific primers for the above genes were designed using Premier 5 software as follows:

TSG-6-up: GCAGCTAGAAGCAGCCAGAAAG, TSG-6-dn: TTGTAGCAATAGGCGTCCCACC; NF-kB-up: CTACACTTAGCCATCATCCACCTT, NF-kB-dn: AGTCCTCCACCACATCTTCCTG; GAPDH-up: AAGGTGAAGGTCGGAGTCAA, GAPDH-dn: AATGAAGGGGTCATTGATGG.

The $2^{-\Delta \Delta C t}$ method was used to calculate the relative expression levels.

\section{Western blot analysis}

Total protein was isolated from rat injured brain tissues using ice-cold RIPA buffer. Total protein concentrations were measured with the BCA Protein Assay Kit (Thermo). Protein samples (30 $\mu \mathrm{g}$ per lane) were separated using sodium dodecyl sulfate-polyacrylamide gel electrophoresis and transferred to polyvinylidene difluoride membranes. Proteins were detected by incubation with primary antibodies (mouse polyclonal to TSG- 6 and mouse anti-NF-kB p65 1:250, BD Biosciences, San Jose, CA, USA) followed by secondary antibodies (goat anti- mouse IgG, horseradish-peroxidase conjugate, 1:1,000, Sigma Aldrich, St. Louis, MO, USA). Immunoblots were visualized using a Millipore ECL Western Blotting Detection System (Millipore, Billerica, MA, USA). GAPDH (1:3,000, Santa Cruz Biotechnology, Santa Cruz, CA, USA.) was employed as the loading control.

\section{Statistical analysis}

Statistical analyses were performed using SPSS version 13.0 (SPSS, Chicago, IL, USA), and all data are presented as mean \pm S.D. Statistical differences among the groups were assessed by one-way ANOVA and post hoc multiple comparisons were performed using Student-Newman-Keuls tests. The significance level was set at $p<0.05$.

\section{Results}

Isolation and characterization of MSCs

MSCs were isolated from SD rats' bone marrow and maintained in culture for several passages. Before intravenous transplantation, third- and eighth-passage cells were characterized, and flow cytometry analysis confirmed that the cells at transplantation were positive for CD44 (99.01\%), CD90 (99.28\%) and CD105 (97.71\%), and had low expression of CD14 (0.79\%), CD34 (0.78\%), CD45 (0.67\%) and HLA-DR (1.11\%) (Figure 1).

\section{Treatment with MSCs improved neurological recovery after TBI}

In order to assess the effects of systemic administration of MSCs after TBI, mNSS was performed on days 1, 3, 7, 14, 21 and 28 after TBI. There was a significant improvement in neurological function in the MSC-treated group compared with the PBS group from days 3-28 post-TBI $(p<0.05)$. There was no significant difference between the scores in the two groups only at $24 \mathrm{~h}$ post-TBI (Figure 2A).

\section{MSC treatment reduced brain water content after TBI}

To investigate whether treatment with MSCs could reduce brain edema, we measured brain water contents in the two experimental groups. Increased water content directly causes brain edema, which is one of the most important surrogate markers of brain damage, and it peaks at $72 \mathrm{~h}$ after brain injury [44]. The PBS group had a significantly higher brain water content than the sham-injured control group. However, treatment with MSCs significantly reduced the brain water contents compared with the PBS group $(p<0.05)$. The brain water contents in the sham, PBS and MSC groups were $78.62 \pm 0.32,82.48 \pm 0.74 \%$ and $79.87 \pm 0.70 \%$, respectively (Figure 2B).

\section{MSC treatment reduced brain inflammatory cell infiltration, microglia and apoptotic cell numbers}

To test the effects of MSC treatment on the number of peripheral infiltrating and resident immune cells in the injured brain, we identified $\mathrm{GFAP}^{+}$astrocytes, Iba- $1^{+}$ microglia cells/macrophages, $\mathrm{MPO}^{+}$neutrophils and $\mathrm{CD}^{+}$lymphocytes by immunohistochemistry. The densities of astrocytes were not significantly different after MSC treatment (Figure 3B,D). The number of microglia/ macrophages (sham: $142.7 \pm 45.4$ cells $/ \mathrm{mm}^{2}$; PBS: 1,524 . $7 \pm 60.1$ cells $/ \mathrm{mm}^{2}$; MSCs: $1,124.3 \pm 104.5$ cells $/ \mathrm{mm}^{2}$ ) (Figure 3C,E) was significantly reduced after MSC 

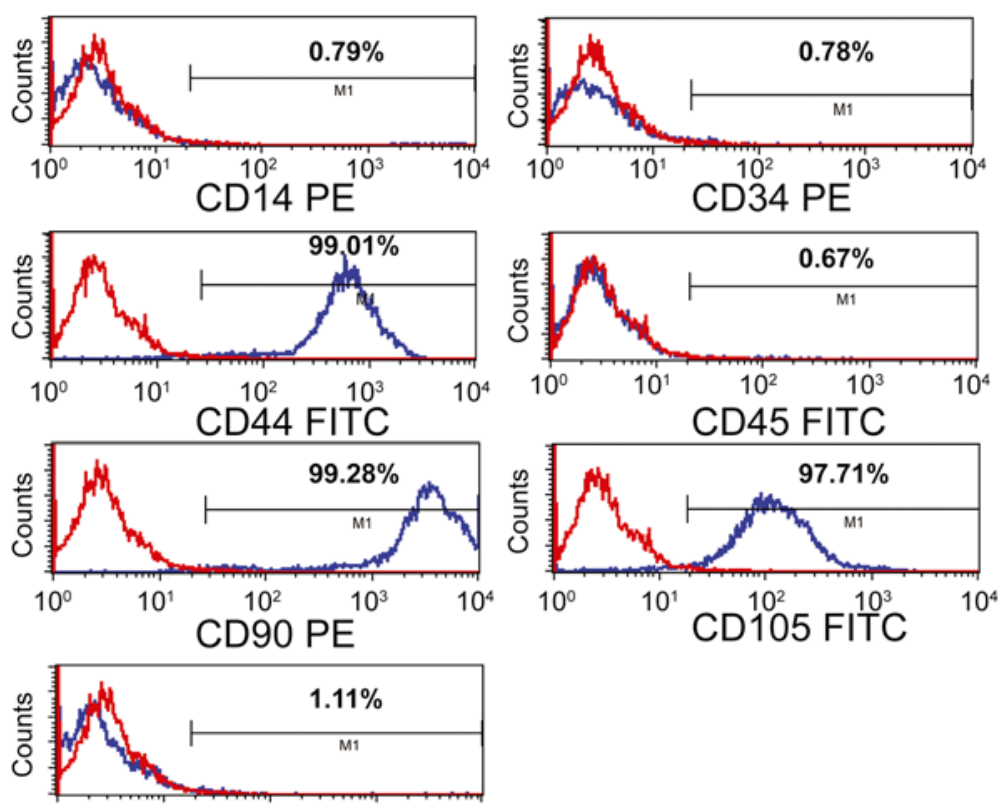

HLA-DR PE

Figure 1 Surface marker expression in MSCs. MSCs were confirmed by flow cytometry analysis after three passages as positive for CD44 (99.01\%), CD90 (99.28\%) and CD105 (97.71\%), with low positivity for CD14 (0.79\%), CD34 (0.78\%), CD45 (0.67\%) and HLA-DR (1.11\%).

administration at $72 \mathrm{~h}$ post-TBI compared with the PBS treatment group $(p<0.05)$. Meanwhile, MSCs decreased the densities of infiltrated $\mathrm{MPO}^{+}$neutrophils (PBS: $775.0 \pm$ 55.34 cells $/ \mathrm{mm}^{2}$; MSCs: $638.67 \pm 72.15$ cells $\left./ \mathrm{mm}^{2}\right)$ (Figure 4A,C) and $\mathrm{CD}^{+}$lymphocytes (PBS: $421.67 \pm 28.15$ cells $/ \mathrm{mm}^{2}$; MSCs: $367.67 \pm 17.5$ cells $/ \mathrm{mm}^{2}$ ) (Figure 4B,D) and apoptotic cells (sham: $18.7 \pm 8.1$ cells $/ \mathrm{mm}^{2}$; PBS: $295 \pm 15$ cells $/ \mathrm{mm}^{2}$; MSCs: $179.3 \pm 25.8$ cells $/ \mathrm{mm}^{2}$ ) (Figure 5$)$ in the injured cortex at $72 \mathrm{~h}$ post-TBI $(p<0.05)$.

\section{MSCs influenced cytokine levels in injured cortex}

To investigate the anti-inflammatory functions of MSCs, we assessed an array of inflammatory cytokines in injured cortex homogenates at 12, 24 and $72 \mathrm{~h}$ after TBI (Figure 6). Levels of the proinflammatory cytokines IL-1 $\beta$ at $12 \mathrm{~h}$ $(p<0.01), 24 \mathrm{~h}(p<0.05)$ and $72 \mathrm{~h}(p<0.05)$, IL-6 at $24 \mathrm{~h}(p<0.05)$ and $72 \mathrm{~h}(p<0.05)$, IL-17 at $24 \mathrm{~h}$ $(p<0.05)$ and $72 \mathrm{~h}(p<0.01)$, TNF- $\alpha$ at $24 \mathrm{~h}(p<0.05)$ and $72 \mathrm{~h}(p<0.01)$, and IFN- $\gamma$ at $72 \mathrm{~h}(p<0.05)$ were all significantly decreased in the MSC-treatment group compared with the PBS group (Figure 6A-E). In contrast, production of the anti-inflammatory cytokines IL-10 at $24 \mathrm{~h}(p<0.01)$ and $72 \mathrm{~h}(p<0.05)$ and TGF- $\beta 1$ at $24 \mathrm{~h}(p<0.01)$ and $72 \mathrm{~h}(p<0.01)$ (Figure 6F,G) after TBI were increased in the MSC-treatment group compared with the PBS group. The chemokines MCP-1,
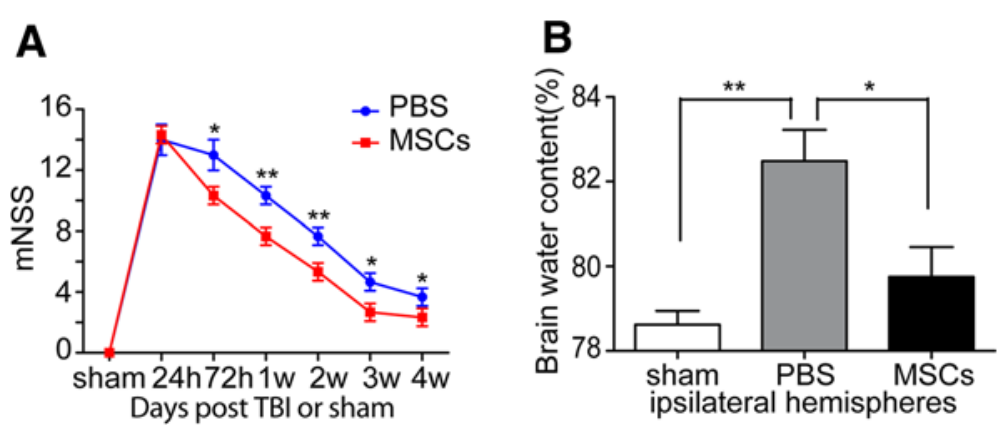

Figure 2 Modified neurologic severity score (mNSS) and brain water content. (A) Neurological function was analyzed by mNSS on days 1 , 3, 7, 14, 21 and 28 after TBI. Treatment with MSCs significantly lowered mNSS from days 3-28 compared with the PBS group. There was no significant difference in scores between the MSC- and PBS-treated groups only at $24 \mathrm{~h}$ post-TBI ( $n=6$ per group). (B) Brain water content of ipsilateral hemispheres was measured at $72 \mathrm{~h}$ after injury. The PBS group had a significantly higher brain water content than the sham-injured control group. MSC treatment significantly reduced brain water content compared with the PBS group ( $n=6$ per group). Data are presented as the mean $\pm S D .{ }^{*} p<0.05,{ }^{* *} p<0.01$. 
A
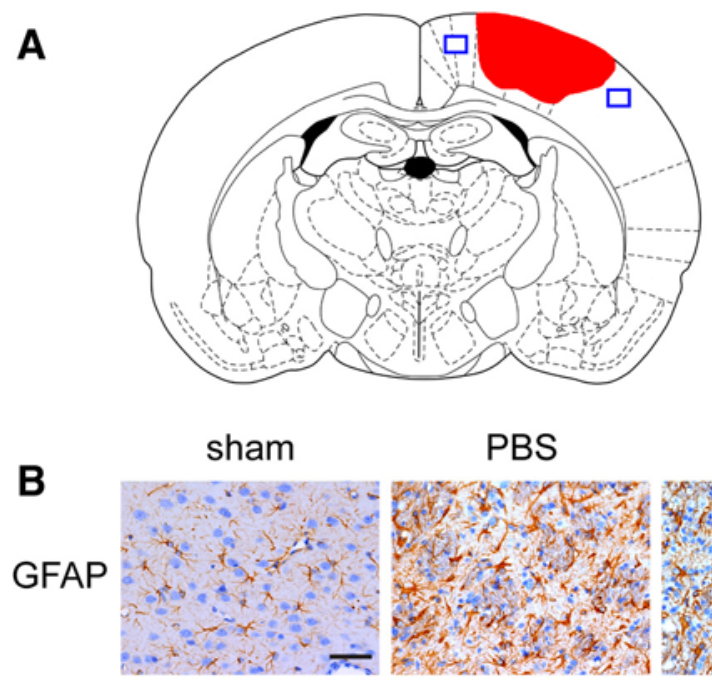

PBS

MSCs

Negative control

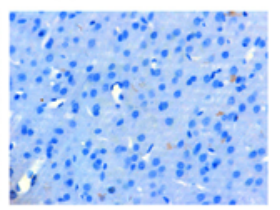

C

IBA-1

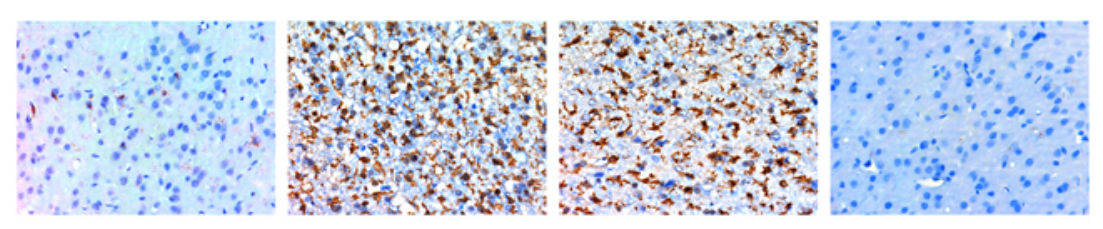

D

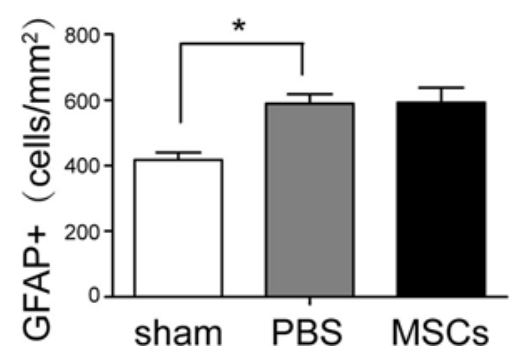

E

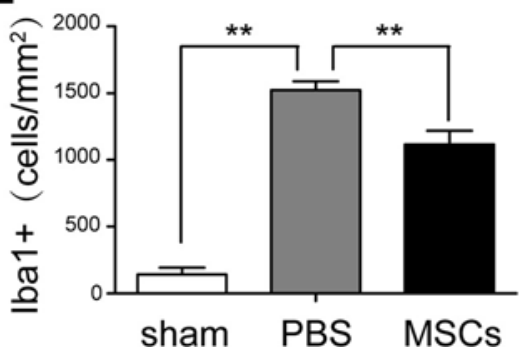

Figure 3 Effect of MSC treatment on GFAP ${ }^{+}$astrocytes and Iba- ${ }^{+}$microglia/macrophages. (A) Diagram of a coronal rat brain section showing the relationship of the lesion cavity (red) to the regions photographed (blue squares). The density of astrocytes was not significantly different after MSC treatment (B, D) $\left(n=6\right.$ per group). The number of microglia/macrophages (C, E) (sham: $142.7 \pm 45.4$ cells $/ \mathrm{mm}^{2} ;$ PBS: $1,524.7 \pm 60.1$ cells $/ \mathrm{mm}^{2}$; MSCs: 1,124.3 \pm 104.5 cells $/ \mathrm{mm}^{2}$ ) was significantly decreased after MSC administration at $72 \mathrm{~h}$ post-TBl compared with the PBS-treatment group ( $n=6$ per group). Data are presented as mean $\pm \mathrm{SD}$. Bar $=50 \mu \mathrm{m} .{ }^{*} p<0.05$.

MIP-2 and RANTES were reduced at 12, 24 and $72 \mathrm{~h}$ after TBI in the MSC group compared with the PBS group (Figure $6 \mathrm{H}-\mathrm{J})$. There were no significant differences in levels of the cytokines IL-1 $\alpha$ and IL-4 (Figure 6K,L) between the two groups.

\section{MSC treatment upregulated TSG- 6 expression}

To elucidate the potential mechanisms responsible for the effects of MSCs on anti-inflammatory and immunomodulatory properties, we analyzed the expression of the inhibitory factors TSG-6 and transcription factor NF- $\kappa B$ at the mRNA and protein levels. TSG- 6 was upregulated from $12-72 \mathrm{~h}$ in the injured cortex after TBI in the MSC-treatment group $(p<0.01)$ (Figure 7A). mRNA levels of NF- $\kappa B$ (Figure $7 \mathrm{~B}$ ) were decreased from
12-48 h after MSC transplantation $(p<0.01)$. Similar results were obtained by Western blotting for TSG-6 and NF-kB p65 (Figure 7C).

\section{Discussion}

In this study, we investigated the anti-inflammatory and immunomodulatory properties of MSCs by systemic transplantation into TBI model rats. The main observations were that MSC treatment reduced the presence of microglia/macrophages in the damaged brain parenchyma and decreased the density of peripheral infiltrating leukocytes at the injured site, as well as reducing proinflammatory cytokines and increasing anti-inflammatory cytokines, possibly through enhanced expression of TSG-6. TSG-6 may, in turn, act by suppressing activation of the NF- $\mathrm{kB}$ signaling 

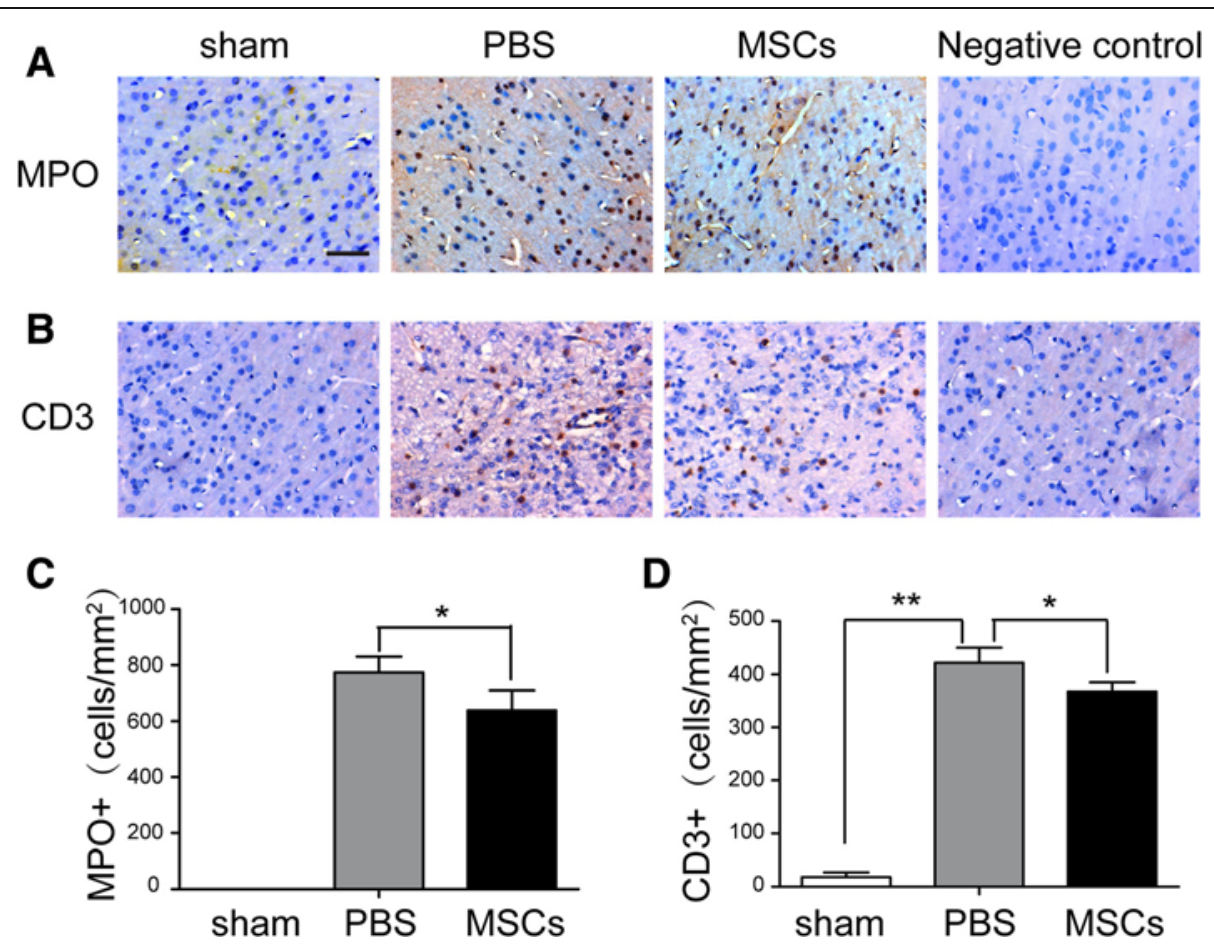

Figure 4 Influence of MSC administration on $\mathrm{MPO}^{+}$neutrophils and $\mathrm{CD}^{+}$lymphocytes. MSCs reduced the numbers of infiltrating MPO $^{+}$neutrophils (A, C) (PBS: $775.0 \pm 55.34$ cells $/ \mathrm{mm}^{2}$; MSCs: $638.67 \pm 72.15$ cells $/ \mathrm{mm}^{2}$ ), CD3 ${ }^{+}$lymphocytes (B, D) (PBS: $421.67 \pm 28.15$ cells $/ \mathrm{mm}^{2}$; MSCs: $367.67 \pm 17.5$ cells $/ \mathrm{mm}^{2}$ ). Data are presented as the mean \pm SD. Bar $=50 \mu \mathrm{m} ; n=6$ per group, ${ }^{*} p<0.05$.

pathway and decreasing the production of proinflammatory cytokines to initiate a proinflammatory cytokine cascade.

Proinflammatory cytokines such as TNF- $\alpha$, IL-1 and IL-6 are produced mainly by microglia, with some also produced by astrocytes, neurons and endothelial cells, which in turn activate glial cells, inducing further cytokine production and astrogliosis $[4,45,46]$. Reduced activation of microglia can thus reduce inflammation and improve histological and functional outcomes after TBI [8]. Anti-inflammatory cytokines such as IL-4, IL-10 and TGF- $\beta 1$ have the ability to counteract and downregulate inflammatory and cytotoxic reactions $[4,47]$. For instance, IL-10 is produced by microglia and astrocytes and by lymphocytes in the periphery, and can suppress microglia and astroglia activation, as

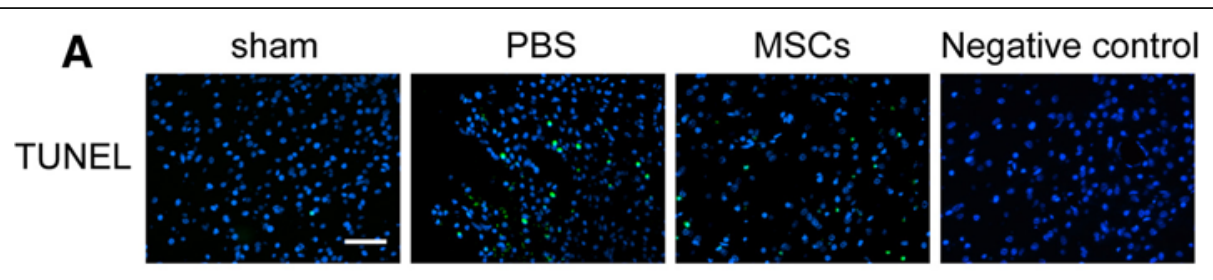

B

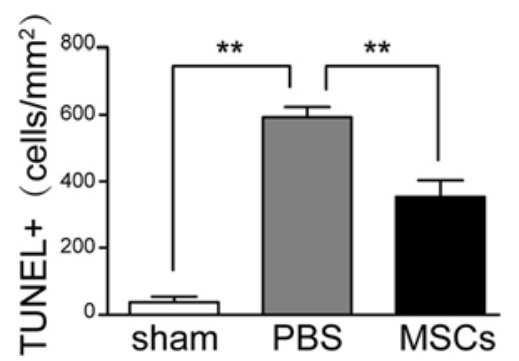

Figure 5 Effect of MSC transplantation on apoptosis. Apoptotic cells (sham: $18.7 \pm 8.1 \mathrm{cells} / \mathrm{mm}^{2} ; \mathrm{PBS}: 295 \pm 15 \mathrm{cells} / \mathrm{mm}^{2}$; MSCs: $179.3 \pm 25.8$ cells $/ \mathrm{mm}^{2}$ ) in the injured cortex at $72 \mathrm{~h}$ after TBI were reduced in the MSC treatment group compared with the PBS group (A, B) $\left(n=6\right.$ per group). Number of apoptotic cells is presented as the mean \pm SD. Bar $=50 \mu \mathrm{m} .{ }^{* *} p<0.01$. 

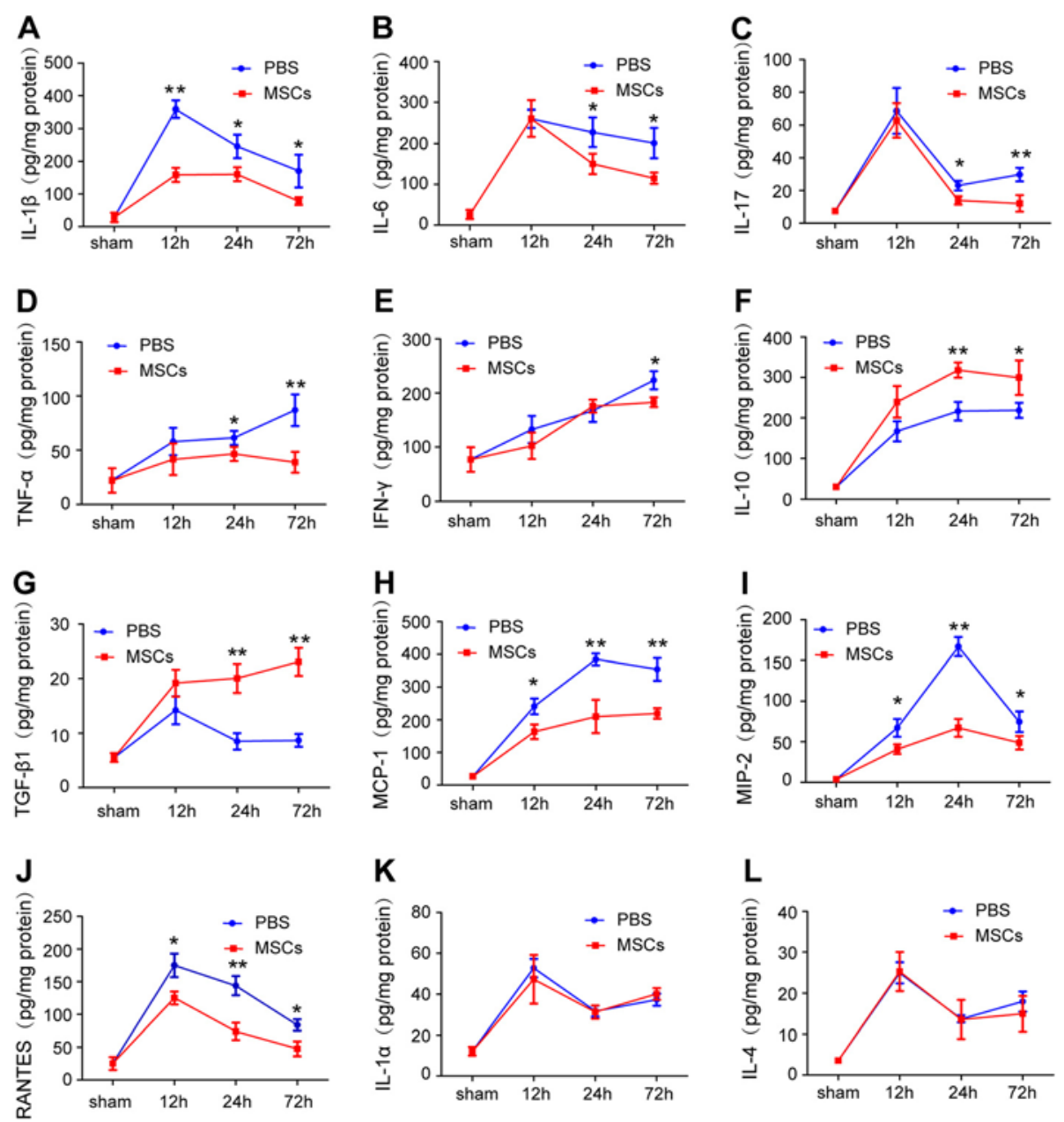

Figure 6 Influence of MSC treatment on cytokine concentrations. Levels of the proinflammatory cytokines IL-1 (at 12, 24 and 72 h), IL-6 (at 24 and 72 h), IL-17 (at 24 and 72 h), TNF-a (at 24 and 72 h) and IFN- $\gamma$ (at 72 h) were significantly decreased in the MSC-treatment group compared with the PBS group (A-E). Levels of the anti-inflammatory cytokines IL-10 and TGF- $\beta 1$ (at 24 and $72 \mathrm{~h}$ after TBI) (F, G) were increased in the MSC-treatment group compared with the PBS group. The chemokines MCP-1, MIP-2 and RANTES were reduced at 12, 24 and $72 \mathrm{~h}$ after TBI in the MSC group compared with the PBS group $(\mathbf{H}-\mathbf{J})$. There were no significant differences in levels of the cytokines IL-1a and IL-4 (K, L) between the two groups. $n=6$ in each time point of per group. Data are presented as the mean \pm SD. ${ }^{*} p<0.05,{ }^{* *} p<0.01$.

well as decreasing production of proinflammatory cytokines [48,49]. MSCs have been shown to decrease proinflammatory cytokine gene expression in experimental acute lung injury [31,32], myocardial infarction [33] and acute renal failure [34] and to upregulate IL-10 expression in rat models of myocardial infarction and cerebral infarction [50,51]. Although astrocytes are not directly immune-related cells, activated astrocytes are a major source of inflammatory-related molecules such as pro- and anti-inflammatory cytokines and chemokines. In addition, astrocyte activation and proliferation after TBI seem to impair axonal regrowth, but these cells also release neurotrophic factors promoting tissue repair and neurogenesis [52]. However, the immunomodulatory effects of MSCs on astrocytes are still limited. One study has shown that MSCs can inhibit the production of cytokines in LPS-activated astrocyte cultures, reducing not only the proinflammatory cytokines, but also the expression of the anti-inflammatory IL-10 [53].

In the CNS, chemokines secreted by glia and neurons are considered to be essential mediators in the recruitment of leukocytes into damaged parenchyma in post-traumatic neuroinflammation [43]. MIP-2, also known as CXCL2, contributes to neutrophil infiltration and subsequent secondary neurodegeneration following TBI [54], and it has been shown to increase rapidly following TBI in experimental TBI models [55,56]. MCP-1, also known as CCL2, is the most potent chemoattractant for monocytes, macrophages and microglia, which play significant roles in mediating post-traumatic secondary brain damage [43]. CCL2 expression is elevated rapidly after diffuse axonal injury, and its overexpression exacerbated ischemic brain injury in 


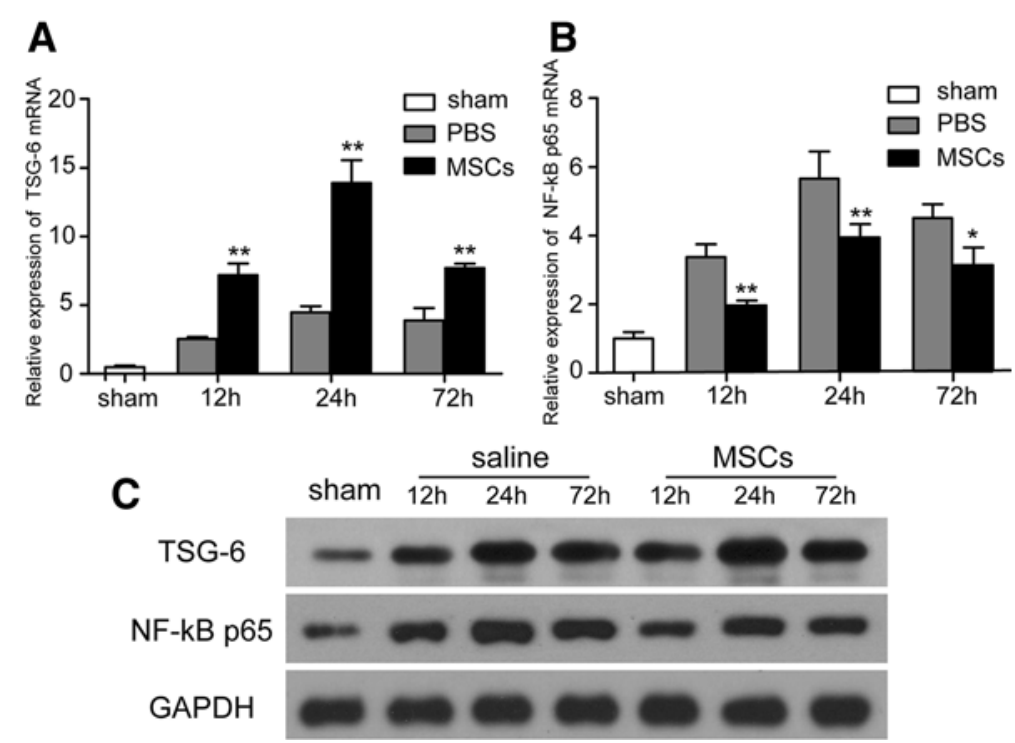

Figure 7 MSC treatment upregulates TSG-6 and downregulates NF-KB expression. Upregulation of TSG-6 (A) was observed from 12 to $72 \mathrm{~h}$ in the injured cortex after TBI in the MSC-treatment group. mRNA levels of NF-KB (B) decreased from 12 to $48 \mathrm{~h}$ after MSC transplantation. Similar results were observed at the protein level (C) for TSG-6 and NF-kB p65. $n=6$ in each time point of per group. Data are presented as the mean \pm SD. ${ }^{*} p<0.05,{ }^{* *} p<0.01$ versus PBS group.

mice $[57,58]$. Expression of the chemokine RANTES (regulated upon activation, normal $\mathrm{T}$ cell expressed and secreted) increased after brain injury in rats and has the ability to activate $\mathrm{T}$ cells [59]. The role of $\mathrm{T}$ lymphocytes in TBI is largely unknown, although in ischemic stroke, these cells infiltrate into the brain and release proinflammatory cytokines and cytotoxic substances, which contribute to early inflammation and brain injury [10]. One study has shown that reduction of T-lymphocyte recruitment significantly enhances tissue preservation and functional outcome after spinal cord injury [60]. Therefore, reduction of neutrophil and $\mathrm{T}$ lymphocyte infiltrations at an early stage is a key feature in improving TBI outcome [61]. In contrast, $\mathrm{T}$ lymphocytes can also have beneficial effects on the repair and regeneration of the brain at later stages following injury [10]. Our results indicated that MSCs reduce production of the chemokines MIP-2, MCP-1 and RANTES, suggesting that they could act through reducing chemokine production, thus decreasing the recruitment of peripheral leukocytes.

The anti-inflammatory and immunosuppressive effects of MSCs were related to several inhibitory factors such as inducible nitric oxide synthase, indoleamine 2,3-dioxygenase, prostaglandin E2 and TSG-6, which are produced by MSCs or released following cross-talk with target cells, and which have been reported to be involved in MSC-mediated immune regulation [22]. The current study did not investigate inhibitory factors produced by MSCs, such as inducible nitric oxide synthase, indoleamine 2,3-dioxygenase or prostaglandin E2, because their short half-lives mean that their immunosuppressive effects can only be observed in vitro or because they have adverse effects when administered systemically [62]. TSG-6 is an anti-inflammatory protein with multiple anti-inflammatory effects that is induced by the inflammatory cytokines TNF- $\alpha$ and IL-1 [63]. Transplanted MSCs played a crucial role in the suppression of inflammation in models of myocardial infarction and corneal injury, and these anti-inflammatory effects may be attributable to the secretion of TSG-6 by MSCs [33,64]. NF-kB is an important transcription factor that regulates many genes with key roles in immune and inflammatory responses. It is activated in the brain after TBI and contributes to neuronal death $[65,66]$. Inhibition of NF-kB activation may thus reduce adverse inflammatory response events and reduce the loss of neuronal cells after TBI. TSG- 6 can reduce the production of proinflammatory cytokines through suppressed activation of the NF- $\mathrm{kB}$ signaling pathway, thus initiating the cascade of proinflammatory cytokines [67]. Our results suggest that the beneficial effects of MSCs may be partially explained by the effect of TSG- 6 on the NF-kB pathway.

The results of this study raise several issues regarding the clinical use of MSCs. First, the schedule of MSC administration is important. MSCs are not spontaneously immunosuppressive and only exhibit this property under special conditions [22]; stimulation with certain inflammatory cytokines such as IFN- $\gamma$ is essential for MSC-mediated immunosuppression [68]. If the levels of inflammatory cytokines are too low, the immunosuppressive effect of 
MSCs will not be triggered. Inflammatory cytokines are rapidly upregulated following brain injury, and some peak at as little as $2 \mathrm{~h}$ after TBI [7]. In addition, neutrophil and T lymphocyte infiltrations peak at $24 \mathrm{~h}$ after TBI [61], and microglia activation is induced immediately after injury $[69,70]$. Later MSC treatment may therefore not be effective in terms of anti-inflammatory or immunosuppressive activity, while MSC administration at the onset of the inflammatory response after TBI is more likely to be effective. In this study, we therefore transplanted MSCs at $2 \mathrm{~h}$ after TBI. Second, the route taken by the cells is also important. Previous studies showed that in the case of intravenously injected MSCs, few cells reached the brain parenchyma after the pulmonary first-pass effect [16]. The ideal treatment combined intravenous injection with direct injection to provide both systemic and local therapeutic effects [21]. Finally, multiple administrations of MSCs may be needed to sustain and prolong their inhibitory effects, as demonstrated in a mouse graft-versus-host disease model [71].

MSCs are known to modulate both systemic and local inflammation systems in neuroinflammation [72]. We did not investigate the effect of MSCs on systemic inflammation, but the possibility that the neuroprotective effects of MSCs are caused by modulation of the systemic inflammatory system cannot be ruled out. Recent evidence suggests a link between brain injury and the autonomic release of proinflammatory cytokines by resident macrophages in the spleen [73]. Inhibiting this release by splenectomy was shown to improve outcomes in animal models of TBI [44], implying that transplanted MSCs acting directly on resident macrophages in the spleen could contribute to the neuroprotective effect. Overall, these results suggest that novel MSC-mediated immunosuppression mechanisms may be developed for the therapy of TBI.

\section{Conclusions}

These results suggest that MSCs have the ability to modulate inflammation-associated cytokine release and immune cells in TBI-induced cerebral inflammatory responses. This study serves as the basis for future studies and offers new insights into the mechanisms responsible for the beneficial immunomodulatory effect of MSC transplantation in terms of functional neurological recovery after TBI. However, further studies are needed to resolve outstanding issues regarding the clinical use of MSCs in TBI.

\section{Abbreviations}

MSC: Mesenchymal stem cell; TBI: Traumatic brain injury; CNS: Central nervous system; mNSS: Modified neurologic severity score; TSG-6: Stimulated gene/protein 6; NF-kB: Nuclear factor-kB.

\section{Competing interests}

The authors declare that they have no competing interests.

\section{Authors' contributions}

Conceived and designed the experiments: RZ, XDJ. Performed the experiments: RZ, YL, KY, XRC, LC. Analyzed the data: FFC, PL. Wrote the paper: RZ, XDJ. Paper revision: XDJ. All authors read and approved the final manuscript.

\section{Acknowledgments}

This work was supported by grants from the funds for National Key Clinic Department, the Natural Science Fund of China (nos. 81171179, 81272439), the Funds for Key Sci-Tech Research Projects of Guangdong (no. 2008A030201019) and Guangzhou (no. 09B52120112-2009J1-C418-2, no. 2008A1-E4011-6) to Prof. Xiaodan Jiang.

\section{Author details}

${ }^{1}$ The National Key Clinic Specialty, The Neurosurgery Institute of Guangdong Province, Guangdong Provincial Key Laboratory on Brain Function Repair and Regeneration, Department of Neurosurgery, Zhujiang Hospital, Southern Medical University, Guangzhou 510282, China. ²Department of Neurosurgery, Shenzhen Second People's Hospital, the First Affiliated Hospital of Shenzhen University, Shenzhen 518000, China.

Received: 25 June 2013 Accepted: 19 August 2013

Published: 23 August 2013

\section{References}

1. Xiong Y, Mahmood A, Chopp M: Neurorestorative treatments for traumatic brain injury. Discov Med 2010, 10:434-442.

2. Helmy A, Carpenter KL, Menon DK, Pickard JD, Hutchinson PJ: The cytokine response to human traumatic brain injury: temporal profiles and evidence for cerebral parenchymal production. J Cereb Blood Flow Metab 2011, 31:658-670.

3. Correale J, Villa A: The neuroprotective role of inflammation in nervous system injuries. J Neurol 2004, 251:1304-1316

4. Ziebell JM, Morganti-Kossmann MC: Involvement of pro- and anti-inflammatory cytokines and chemokines in the pathophysiology of traumatic brain injury. Neurotherapeutics 2010, 7:22-30.

5. Rhodes J: Peripheral immune cells in the pathology of traumatic brain injury? Curr Opin Crit Care 2011, 17:122-130.

6. Lucas SM, Rothwell NJ, Gibson RM: The role of inflammation in CNS injury and disease. Br J Pharmacol 2006, 147(Suppl 1):S232-S240.

7. Helmy A, De Simoni MG, Guilfoyle MR, Carpenter KL, Hutchinson PJ: Cytokines and innate inflammation in the pathogenesis of human traumatic brain injury. Prog Neurobiol 2011, 95:352-372.

8. d'Avila JC, Lam TI, Bingham D, Shi J, Won SJ, Kauppinen TM, Massa S, Liu J, Swanson RA: Microglial activation induced by brain trauma is suppressed by post-injury treatment with a PARP inhibitor. J Neuroinflammation 2012, 9:31.

9. Morganti-Kossmann MC, Satgunaseelan L, Bye N, Kossmann T: Modulation of immune response by head injury. Injury 2007, 38:1392-1400.

10. Brait VH, Arumugam TV, Drummond GR, Sobey CG: Importance of T lymphocytes in brain injury, immunodeficiency, and recovery after cerebral ischemia. J Cereb Blood Flow Metab 2012, 32:598-611.

11. Arneth BM: Protective autoimmunity and protein localization. J Neuroimmunol 2010, 219:123-125.

12. Winter $C D$, Pringle $A K$, Clough GF, Church MK: Raised parenchymal interleukin-6 levels correlate with improved outcome after traumatic brain injury. Brain 2004, 127:315-320.

13. Turrin NP, Rivest S: Tumor necrosis factor alpha but not interleukin 1 beta mediates neuroprotection in response to acute nitric oxide excitotoxicity. J Neurosci 2006, 26:143-151.

14. Biber K, Neumann H, Inoue K, Boddeke HW: Neuronal 'on' and 'off' signals control microglia. Trends Neurosci 2007, 30:596-602.

15. Aloisi F: Immune function of microglia. Glia 2001, 36:165-179.

16. Parr AM, Tator $\mathrm{CH}$, Keating A: Bone marrow-derived mesenchymal stromal cells for the repair of central nervous system injury. Bone Marrow Transplant 2007, 40:609-619.

17. Chopp M, Li Y: Treatment of neural injury with marrow stromal cells. Lancet Neurol 2002, 1:92-100

18. Si YL, Zhao YL, Hao HJ, Fu XB, Han WD: MSCs: Biological characteristics, clinical applications and their outstanding concerns. Ageing Res Rev 2011, 10:93-103. 
19. Scuteri A, Miloso M, Foudah D, Orciani M, Cavaletti G, Tredici G: Mesenchymal stem cells neuronal differentiation ability: a real perspective for nervous system repair? Curr Stem Cell Res Ther 2011, 6:82-92.

20. Meirelles Lda S, Fontes AM, Covas DT, Caplan Al: Mechanisms involved in the therapeutic properties of mesenchymal stem cells. Cytokine Growth Factor Rev 2009, 20:419-427.

21. Uccelli A, Moretta L, Pistoia V: Mesenchymal stem cells in health and disease. Nat Rev Immunol 2008, 8:726-736.

22. Shi Y, Su J, Roberts Al, Shou P, Rabson AB, Ren G: How mesenchymal stem cells interact with tissue immune responses. Trends Immunol 2012, 33:136-143.

23. Di Nicola M, Carlo-Stella C, Magni M, Milanesi M, Longoni PD, Matteucci P, Grisanti S, Gianni AM: Human bone marrow stromal cells suppress T-lymphocyte proliferation induced by cellular or nonspecific mitogenic stimuli. Blood 2002, 99:3838-3843.

24. Ooi YY, Ramasamy R, Rahmat Z, Subramaiam H, Tan SW, Abdullah M, Israf DA, Vidyadaran S: Bone marrow-derived mesenchymal stem cells modulate BV2 microglia responses to lipopolysaccharide. Int Immunopharmacol 2010, 10:1532-1540.

25. Nemeth K, Leelahavanichkul A, Yuen PS, Mayer B, Parmelee A, Doi K, Robey PG, Leelahavanichkul K, Koller BH, Brown JM, et al: Bone marrow stromal cells attenuate sepsis via prostaglandin $\mathrm{E}(2)$-dependent reprogramming of host macrophages to increase their interleukin-10 production. Nat Med 2009, 15:42-49.

26. Raffaghello L, Bianchi G, Bertolotto M, Montecucco F, Busca A, Dallegri F, Ottonello L, Pistoia V: Human mesenchymal stem cells inhibit neutrophil apoptosis: a model for neutrophil preservation in the bone marrow niche. Stem Cells 2008, 26:151-162.

27. Zappia E, Casazza S, Pedemonte E, Benvenuto F, Bonanni I, Gerdoni E, Giunti D, Ceravolo A, Cazzanti F, Frassoni F, et al: Mesenchymal stem cells ameliorate experimental autoimmune encephalomyelitis inducing T-cell anergy. Blood 2005, 106:1755-1761

28. Gerdoni E, Gallo B, Casazza S, Musio S, Bonanni I, Pedemonte E, Mantegazza R, Frassoni F, Mancardi G, Pedotti R, Uccelli A: Mesenchymal stem cells effectively modulate pathogenic immune response in experimental autoimmune encephalomyelitis. Ann Neurol 2007, 61:219-227.

29. Le Blanc K, Rasmusson I, Sundberg B, Gotherstrom C, Hassan M, Uzunel M, Ringden O: Treatment of severe acute graft-versus-host disease with third party haploidentical mesenchymal stem cells. Lancet 2004, 363:1439-1441.

30. Stemberger S, Jamnig A, Stefanova N, Lepperdinger G, Reindl M, Wenning GK: Mesenchymal stem cells in a transgenic mouse model of multiple system atrophy: immunomodulation and neuroprotection. PLOS One 2011, 6:e19808.

31. Ortiz LA, Dutreil M, Fattman C, Pandey AC, Torres G, Go K, Phinney DG: Interleukin 1 receptor antagonist mediates the antiinflammatory and antifibrotic effect of mesenchymal stem cells during lung injury. Proc Natl Acad Sci U S A 2007, 104:11002-11007.

32. Gupta N, Su X, Popov B, Lee JW, Serikov V, Matthay MA: Intrapulmonary delivery of bone marrow-derived mesenchymal stem cells improves survival and attenuates endotoxin-induced acute lung injury in mice. J Immunol 2007, 179:1855-1863.

33. Lee RH, Pulin AA, Seo MJ, Kota DJ, Ylostalo J, Larson BL, Semprun-Prieto L, Delafontaine P, Prockop DJ: Intravenous hMSCs improve myocardial infarction in mice because cells embolized in lung are activated to secrete the anti-inflammatory protein TSG-6. Cell Stem Cell 2009, 5:54-63.

34. Togel F, Hu Z, Weiss K, Isaac J, Lange C, Westenfelder C: Administered mesenchymal stem cells protect against ischemic acute renal failure through differentiation-independent mechanisms. Am J Physiol Renal Physiol 2005, 289:F31-F42.

35. Sheikh AM, Nagai A, Wakabayashi K, Narantuya D, Kobayashi S, Yamaguchi S, Kim SU: Mesenchymal stem cell transplantation modulates neuroinflammation in focal cerebral ischemia: contribution of fractalkine and IL-5. Neurobiol Dis 2011, 41:717-724.

36. Lee JK, Jin HK, Endo S, Schuchman EH, Carter JE, Bae JS: Intracerebral transplantation of bone marrow-derived mesenchymal stem cells reduces amyloid-beta deposition and rescues memory deficits in Alzheimer's disease mice by modulation of immune responses. Stem Cells 2010, 28:329-343.

37. Vendrame M, Gemma C, de Mesquita D, Collier L, Bickford PC, Sanberg CD, Sanberg PR, Pennypacker KR, Willing AE: Anti-inflammatory effects of human cord blood cells in a rat model of stroke. Stem Cells Dev 2005, 14:595-604.
38. Lee ST, Chu K, Jung KH, Kim SJ, Kim DH, Kang KM, Hong NH, Kim JH, Ban JJ, Park HK et al: Anti-inflammatory mechanism of intravascular neural stem cell transplantation in haemorrhagic stroke. Brain 2008, 131:616-629.

39. Aggarwal S, Pittenger MF: Human mesenchymal stem cells modulate allogeneic immune cell responses. Blood 2005, 105:1815-1822.

40. Dominici M, Le Blanc K, Mueller I, Slaper-Cortenbach I, Marini F, Krause D, Deans R, Keating A, Prockop D, Horwitz E: Minimal criteria for defining multipotent mesenchymal stromal cells. The International Society for Cellular Therapy position statement. Cytotherapy 2006, 8:315-317.

41. Feeney DM, Boyeson MG, Linn RT, Murray HM, Dail WG: Responses to cortical injury: I. Methodology and local effects of contusions in the rat. Brain Res 1981, 211:67-77.

42. Lu M, Chen J, Lu D, Yi L, Mahmood A, Chopp M: Global test statistics for treatment effect of stroke and traumatic brain injury in rats with administration of bone marrow stromal cells. J Neurosci Methods 2003, 128:183-190.

43. Semple BD, Bye N, Rancan M, Ziebell JM, Morganti-Kossmann MC: Role of CCL2 (MCP-1) in traumatic brain injury (TBI): evidence from severe TBI patients and CCL2-/- mice. J Cereb Blood Flow Metab 2010, 30:769-782.

44. Li M, Li F, Luo C, Shan Y, Zhang L, Qian Z, Zhu G, Lin J, Feng H: Immediate splenectomy decreases mortality and improves cognitive function of rats after severe traumatic brain injury. J Trauma 2011, 71:141-147.

45. Lau LT, Yu AC: Astrocytes produce and release interleukin-1, interleukin-6, tumor necrosis factor alpha and interferon-gamma following traumatic and metabolic injury. J Neurotrauma 2001, 18:351-359.

46. Konsman JP, Drukarch B, Van Dam AM: (Peri)vascular production and action of pro-inflammatory cytokines in brain pathology. Clin Sci (Lond) 2007, 112:1-25.

47. Cederberg D, Siesjo P: What has inflammation to do with traumatic brain injury? Childs Nerv Syst 2010, 26:221-226.

48. Kremlev SG, Palmer C: Interleukin-10 inhibits endotoxin-induced pro-inflammatory cytokines in microglial cell cultures. J Neuroimmunol 2005, 162:71-80.

49. Knoblach SM, Faden Al: Interleukin-10 improves outcome and alters proinflammatory cytokine expression after experimental traumatic brain injury. Exp Neurol 1998, 153:143-151.

50. Liu N, Chen R, Du H, Wang J, Zhang Y, Wen J: Expression of IL-10 and TNF-alpha in rats with cerebral infarction after transplantation with mesenchymal stem cells. Cell Mol Immunol 2009, 6:207-213.

51. Du YY, Zhou SH, Zhou T, Su H, Pan HW, Du WH, Liu B, Liu QM: Immuno-inflammatory regulation effect of mesenchymal stem cell transplantation in a rat model of myocardial infarction. Cytotherapy 2008, 10:469-478.

52. Bush TG, Puvanachandra N, Horner CH, Polito A, Ostenfeld T, Svendsen CN, Mucke L, Johnson MH, Sofroniew MV: Leukocyte infiltration, neuronal degeneration, and neurite outgrowth after ablation of scar-forming, reactive astrocytes in adult transgenic mice. Neuron 1999, 23:297-308.

53. Schafer S, Calas AG, Vergouts M, Hermans E: Immunomodulatory influence of bone marrow-derived mesenchymal stem cells on neuroinflammation in astrocyte cultures. J Neuroimmunol 2012, 249:40-48.

54. Semple BD, Bye N, Ziebell JM, Morganti-Kossmann MC: Deficiency of the chemokine receptor CXCR2 attenuates neutrophil infiltration and cortical damage following closed head injury. Neurobiol Dis 2010, 40:394-403.

55. Bye N, Habgood MD, Callaway JK, Malakooti N, Potter A, Kossmann T, Morganti-Kossmann MC: Transient neuroprotection by minocycline following traumatic brain injury is associated with attenuated microglial activation but no changes in cell apoptosis or neutrophil infiltration. Exp Neurol 2007, 204:220-233.

56. Rhodes JK, Sharkey J, Andrews PJ: The temporal expression, cellular localization, and inhibition of the chemokines MIP-2 and MCP-1 after traumatic brain injury in the rat. J Neurotrauma 2009, 26:507-525.

57. Rancan M, Otto VI, Hans VH, Gerlach I, Jork R, Trentz O, Kossmann T, Morganti-Kossmann MC: Upregulation of ICAM-1 and MCP-1 but not of MIP-2 and sensorimotor deficit in response to traumatic axonal injury in rats. J Neurosci Res 2001, 63:438-446.

58. Chen Y, Hallenbeck JM, Ruetzler C, Bol D, Thomas K, Berman NE, Vogel SN: Overexpression of monocyte chemoattractant protein 1 in the brain exacerbates ischemic brain injury and is associated with recruitment of inflammatory cells. J Cereb Blood Flow Metab 2003, 23:748-755.

59. Lumpkins K, Bochicchio GV, Zagol B, Ulloa K, Simard JM, Schaub S, Meyer W, Scalea T: Plasma levels of the beta chemokine regulated upon activation, 
normal T cell expressed, and secreted (RANTES) correlate with severe brain injury. J Trauma 2008, 64:358-361.

60. Gonzalez R, Glaser J, Liu MT, Lane TE, Keirstead HS: Reducing inflammation decreases secondary degeneration and functional deficit after spinal cord injury. Exp Neurol 2003, 184:456-463.

61. Clausen F, Lorant T, Lewen A, Hillered L: T lymphocyte trafficking: a novel target for neuroprotection in traumatic brain injury. J Neurotrauma 2007, 24:1295-1307.

62. Prockop DJ, Oh JY: Mesenchymal stem/stromal cells (MSCs): role as guardians of inflammation. Mol Ther 2012, 20:14-20

63. Wisniewski HG, Vilcek J: TSG-6: an IL-1/TNF-inducible protein with antiinflammatory activity. Cytokine Growth Factor Rev 1997, 8:143-156.

64. Roddy GW, Oh JY, Lee RH, Bartosh TJ, Ylostalo J, Coble K, Rosa RH Jr, Prockop DJ: Action at a distance: systemically administered adult stem/ progenitor cells (MSCs) reduce inflammatory damage to the cornea without engraftment and primarily by secretion of TNF-alpha stimulated gene/protein 6. Stem Cells 2011, 29:1572-1579.

65. Chen G, Shi J, Ding Y, Yin H, Hang C: Progesterone prevents traumatic brain injury-induced intestinal nuclear factor kappa B activation and proinflammatory cytokines expression in male rats. Mediators Inflamm 2007, 2007:93431.

66. Qu C, Mahmood A, Ning R, Xiong Y, Zhang L, Chen J, Jiang H, Chopp M: The treatment of traumatic brain injury with velcade. J Neurotrauma 2010, 27:1625-1634.

67. Choi H, Lee RH, Bazhanov N, Oh JY, Prockop DJ: Anti-inflammatory protein TSG-6 secreted by activated MSCs attenuates zymosan-induced mouse peritonitis by decreasing TLR2/NF-kappaB signaling in resident macrophages. Blood 2011, 118:330-338,

68. Ren G, Zhang L, Zhao X, Xu G, Zhang Y, Roberts Al, Zhao RC, Shi Y: Mesenchymal stem cell-mediated immunosuppression occurs via concerted action of chemokines and nitric oxide. Cell Stem Cell 2008, 2:141-150.

69. Koshinaga M, Katayama Y, Fukushima M, Oshima H, Suma T, Takahata T: Rapid and widespread microglial activation induced by traumatic brain injury in rat brain slices. J Neurotrauma 2000, 17:185-192.

70. Koshinaga M, Suma T, Fukushima M, Tsuboi I, Aizawa S, Katayama Y: Rapid microglial activation induced by traumatic brain injury is independent of blood brain barrier disruption. Histol Histopathol 2007, 22:129-135.

71. Yanez R, Lamana ML, Garcia-Castro J, Colmenero I, Ramirez M, Bueren JA: Adipose tissue-derived mesenchymal stem cells have in vivo immunosuppressive properties applicable for the control of the graftversus-host disease. Stem Cells 2006, 24:2582-2591.

72. Kassis I, Grigoriadis N, Gowda-Kurkalli B, Mizrachi-Kol R, Ben-Hur T, Slavin S, Abramsky O, Karussis D: Neuroprotection and immunomodulation with mesenchymal stem cells in chronic experimental autoimmune encephalomyelitis. Arch Neurol 2008, 65:753-761.

73. Rasouli J, Lekhraj R, Ozbalik M, Lalezari P, Casper D: Brain-spleen inflammatory coupling: a literature review. Einstein J Biol Med 2011, 27:74-77.

doi:10.1186/1742-2094-10-106

Cite this article as: Zhang et al:: Anti-inflammatory and immunomodulatory mechanisms of mesenchymal stem cell transplantation in experimental traumatic brain injury. Journal of Neuroinflammation 2013 10:106.

\section{Submit your next manuscript to BioMed Central and take full advantage of:}

- Convenient online submission

- Thorough peer review

- No space constraints or color figure charges

- Immediate publication on acceptance

- Inclusion in PubMed, CAS, Scopus and Google Scholar

- Research which is freely available for redistribution

Submit your manuscript at www.biomedcentral.com/submit
Ciomed Central 